\title{
System Performance of an Integrated Airborne Spacing Algorithm with Ground Automation
}

\author{
Kurt A. Swieringa, Sara R. Wilson†, and Brian T. Baxley ${ }^{\ddagger}$ \\ NASA Langley Research Center, Hampton, VA, 23681, United States
}

\begin{abstract}
The National Aeronautics and Space Administration's (NASA's) first Air Traffic Management (ATM) Technology Demonstration (ATD-1) was created to facilitate the transition of mature ATM technologies from the laboratory to operational use. The technologies selected for demonstration are the Traffic Management Advisor with Terminal Metering (TMA-TM), which provides precise time-based scheduling in the Terminal airspace; Controller Managed Spacing (CMS), which provides controllers with decision support tools to enable precise schedule conformance; and Interval Management (IM), which consists of flight deck automation that enables aircraft to achieve or maintain precise spacing behind another aircraft. Recent simulations and IM algorithm development at NASA have focused on trajectory-based IM operations where aircraft equipped with IM avionics are expected to achieve a spacing goal, assigned by air traffic controllers, at the final approach fix. The recently published IM Minimum Operational Performance Standards describe five types of IM operations. This paper discusses the results and conclusions of a human-in-the-loop simulation that investigated three of those IM operations. The results presented in this paper focus on system performance and integration metrics. Overall, the IM operations conducted in this simulation integrated well with ground-based decisions support tools and certain types of IM operational were able to provide improved spacing precision at the final approach fix; however, some issues were identified that should be addressed prior to implementing IM procedures into real-world operations.
\end{abstract}

\section{Nomenclature}

$\begin{array}{ll}\text { ASTAR } & \text { Airborne Spacing for Terminal Arrival Routes } \\ \text { ATM } & \text { Air Traffic Management } \\ \text { ATD-1 } & \text { ATM Technology Demonstration } \\ \text { CMS } & \text { Controller Managed Spacing } \\ E T A & \text { Estimated Time of Arrival } \\ \text { IMAC } & \text { Interval Management Alternative Clearances Experiment } \\ \text { KDEN } & \text { Denver International Airport } \\ \text { ETA } & \text { Estimated Time of Arrival } \\ F A A & \text { Federal Aviation Administration } \\ I M & \text { Interval Management } \\ \text { NASA } & \text { National Aeronautics and Space Administration } \\ \text { OPD } & \text { Optimized Profile Descent } \\ S D & \text { Standard Deviation } \\ S T A & \text { Scheduled Time of Arrival } \\ S T A R & \text { Standard Terminal Arrival Route } \\ T M A-T M & \text { Traffic Management Advisor with Terminal Metering }\end{array}$

*Research Engineer, Crew Systems and Aviation Operations Branch, NASA LaRC, MS 152, AIAA Member.

$\dagger^{\dagger}$ Research Engineer, Systems Engineering and Engineering Methods Branch, NASA LaRC, MS 290.

${ }^{\ddagger}$ Senior Research Engineer, Crew Systems and Aviation Operations Branch, NASA LaRC, MS 152, AIAA Senior Member. 


\section{Introduction}

THE 2015-2035 Federal Aviation Administration (FAA) Aerospace Forecast predicts that U.S. commercial aviation revenue passenger miles will increase at an average rate of $1.8 \%$ annually over the next 20 years. ${ }^{1}$ By 2035, U.S. commercial air carriers are projected to fly 1.7 trillion available seat-miles - approximately $167 \%$ of the seat-miles flown in 2014. This increase could strain the current air traffic system if capacity and efficiency improvements are not made. To help increase the efficiency of aircraft operations during arrivals, procedures, such as Optimized Profile Descents (OPDs), have been implemented at a number of airports. However, these procedures are not used often during periods of peak traffic due to the lack of precision scheduling and spacing tools, ${ }^{2}$ resulting in sub-optimal arrival operations. The National Aeronautics and Space Administration (NASA) has been developing technologies that are expected to increase the use of efficient arrival procedures during periods of peak traffic.

The goal of NASA's first Air Traffic Management (ATM) Technology Demonstration (ATD-1) is to accelerate the implementation of mature NASA technologies, enabling aircraft to use speed control to remain close to their OPDs during periods of peak traffic. ${ }^{3,4}$ Three NASA technologies were selected to be integrated together to achieve this goal: the Traffic Management Advisor with Terminal Metering (TMA-TM), ${ }^{5,6}$ which provides precise time-based scheduling in the Terminal airspace; Controller Managed Spacing (CMS), ${ }^{7-9}$ which provides Terminal air traffic controllers with decision support tools that enable precise schedule conformance; and Interval Management (IM), which consists of flight deck automation that enables aircraft to achieve or maintain a precise spacing interval behind the preceding aircraft. ${ }^{10,11}$ These technologies extend scheduling into the Terminal airspace and provide pilots and controllers with control mechanisms that increase schedule conformance and improve spacing precision.

Previous human-in-the-loop simulations have investigated the integration of IM with TMA-TM and CMS in the near-term national airspace system. ${ }^{12-14}$ These simulations were focused on analyzing the acceptability and usability of trajectory-based IM operations, where the goal is to achieve a precise spacing interval at the final approach fix. The recently published IM Minimum Operational Performance Standards describe five different types of IM operations: Capture then Maintain (Capture), Achieve-by then Maintain (Cross), Maintain Current Spacing (Maintain), Final Approach Spacing (Space), and IM Turn (Turn). ${ }^{15}$

The objective of the Interval Management Alternative Clearances (IMAC) human-in-the-loop simulation was to evaluate the performance, usability, and acceptability of a subset of these operations: Capture, Cross, and Maintain.

- The goal of the Capture operation is to capture a spacing goal assigned by air traffic control and then maintain that spacing interval to a designated planned termination point. The Capture operation is intended to be less reliant on knowledge of the Traffic aircraft's intended trajectory than the Cross operation; therefore, it uses a new state-based Constant Time Delay (CTD) speed control law that can only be used when the IM and Traffic aircraft are in-trail.

- The goal of the Cross operation is to achieve a spacing goal, assigned by air traffic control, at an achieve-by point and then maintain that spacing interval to a designated planned termination point. The portion of the Cross operation that occurs prior to the achieve-by point uses a trajectory-based speed control law, and the portion of the Cross operation that occurs after the achieve-by point uses the new state-based CTD speed control law. The Cross operation has been investigated in several fast-time and human-in-the-loop simulations. ${ }^{11,14,16-23}$

- The goal of the Maintain operation is to maintain the initial spacing interval between the IM and Traffic aircraft until a designated planned termination point. The Maintain operation uses the same state-based CTD speed control law as the Capture operation; therefore, the IM and Traffic aircraft are required to be in-trail. Furthermore, the Maintain operation is the only IM operation where the spacing goal does not reflect the schedule produced by TMA-TM, since the objective is to maintain the initial spacing interval between the IM and Traffic aircraft instead of a spacing goal provided by air traffic control.

In order to support these operations, NASA's prototype IM software and procedures were updated. The updates included a new state-based CTD speed control law that was added to NASA's Airborne Spacing for Terminal Arrival Routes (ASTAR) spacing algorithm, ${ }^{24}$ new pages on the electronic flight bag display that 
enabled flight crews to enter information for each IM operation, and the pilot and controller procedures were expanded to accommodate the new IM operations.

This human-in-the-loop simulation examined the integration of the Capture, Cross, and Maintain IM operations with the TMA-TM and CMS decision support tools. During high density arrivals into Denver International Airport (KDEN), air traffic controllers used TMA-TM and CMS to help aircraft achieve precise schedule conformance and subject pilots conducted IM operations to achieve or maintain a precise spacing interval. The results and conclusions presented in this paper focus on system performance metrics that describe how well IM integrates with TMA-TM and CMS.

\section{ATD-1 Technologies}

\section{A. Traffic Management Advisor with Terminal Metering (TMA-TM)}

TMA-TM is an enhancement of the Traffic Management Advisor (TMA) that extends metering into the Terminal airspace and provides both Center and Terminal air traffic controllers with a deconflicted arrival schedule. To calculate a deconflicted arrival schedule, TMA-TM uses the predicted trajectory of each aircraft along its projected OPD to compute its Estimated Times of Arrival (ETAs) to a series of meter points. The schedule is then deconflicted at each of the meter points by delaying aircraft until they are properly spaced. With the advent of flex scheduling, aircraft can also be advanced in certain circumstances; however, this capability was not used in this simulation. At a particular distance or time from the

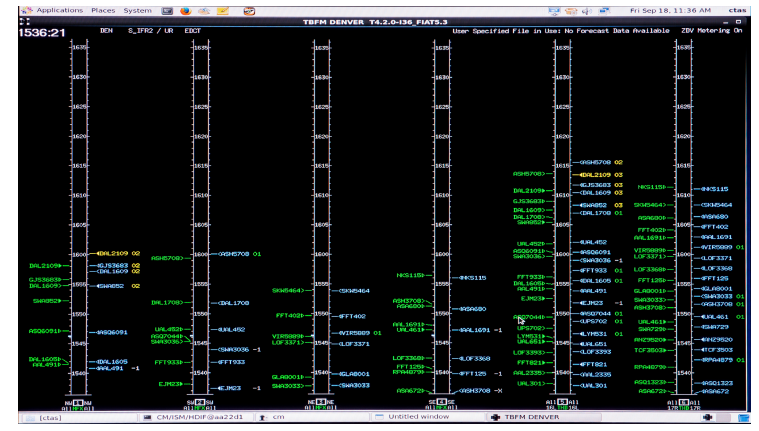

Figure 1. TMA-TM timeline airport, defined as the freeze horizon, TMA-TM locks the Scheduled Times of Arrival (STAs) at each of the meter points, enabling air traffic controllers to work toward a stable schedule.

Both the STAs and ETAs computed by TMA-TM, along with the amount of delay an aircraft must absorb, are shown on timelines to both Center and Terminal controllers (figure 1), who can use decision support tools to help aircraft achieve their STAs. The TMA-TM schedule can also be used to calculate a spacing goal that can be conveyed to an aircraft equipped with IM avionics as part of an IM clearance. The spacing goal is the difference between the STA of the IM aircraft and the STA of the preceding aircraft at a particular meter point, such as the final approach fix.

\section{B. Controller Managed Spacing (CMS)}

CMS is a suite of decision support tools that provide Terminal controllers with advisories that they can use to achieve the schedule computed by TMA-TM. The CMS tools consist of four pieces of information: early/late indicators, slot markers, speed advisories, and a timeline that depicts the TMA-TM schedule (figure 2). The circular slot markers are graphical representations of the schedule that indicate an aircraft's current scheduled location. Speed advisories, displayed on an aircraft's full data block, provide controllers with recommended speeds that they can use to achieve precise schedule conformance at the next meter point. If speed control is inadequate to achieve the STA at the next meter point, the speed advisory is replaced with an early/late indicator. Terminal controllers are also able to display a timeline that depicts the TMA-TM schedule.

Both the TMA-TM and CMS technologies have been

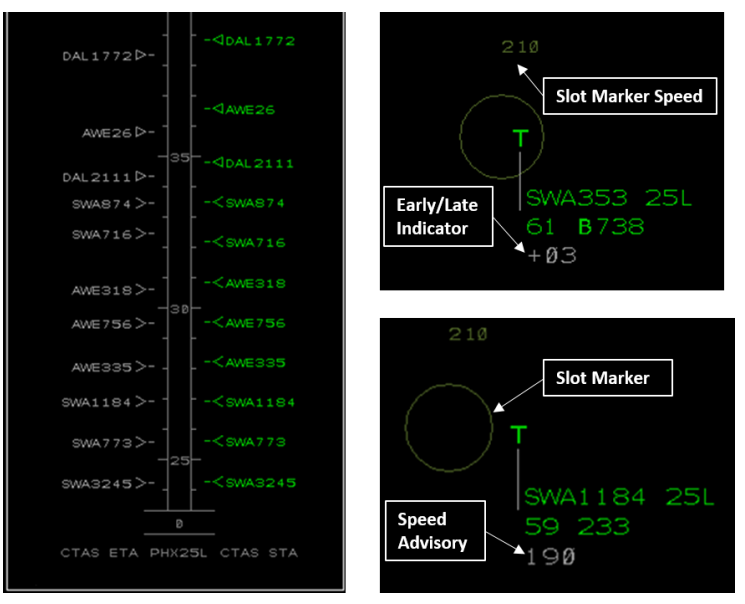

Figure 2. CMS displays transitioned to the FAA, where the Final Investment De- 
cision has been approved as part of the Time-Based Flow Management work package - 3 . The FAA combined the TMA-TM enhancements and the CMS decision support tools into a single tool that is called Terminal Sequencing and Spacing (TSAS). Throughout this paper, the original NASA names are used to maintain consistent terminology with previous research.

\section{Interval Management (IM)}

IM is a flight deck tool that uses on-board avionics to provide flight crews with speeds that they fly to achieve or maintain precise spacing behind a preceding aircraft, which will be referred to as the Traffic aircraft. The primary benefit of IM is derived from increasing the spacing precision between aircraft at a flow constricted point. An increase in spacing precision may allow for smaller spacing buffers, resulting in increased throughput. ${ }^{25}$ The procedure for conducting an IM operation begins when air traffic control provides an appropriately equipped aircraft with an IM clearance. After receiving the clearance, the flight crew loads it into onboard avionics and follows the speeds provided by the IM algorithm to precisely achieve or maintain a spacing goal. For the Capture and Cross operations, the spacing goal is calculated by TMA-TM and conveyed to the flight deck as part of the IM clearance. For the Maintain operation, the spacing goal is calculated by the IM avionics when the operation is initialized.

Prior to ATD-1, most of the IM research conducted at the NASA Langley Research Center assumed an advanced airspace environment with controller-pilot data link communications used to transmit IM clearances to the flight deck, and that the IM aircraft would have access to detailed information of the Traffic aircraft's intended trajectory. When the ATD-1 project began, the focus of IM research at NASA switched from a future environment to

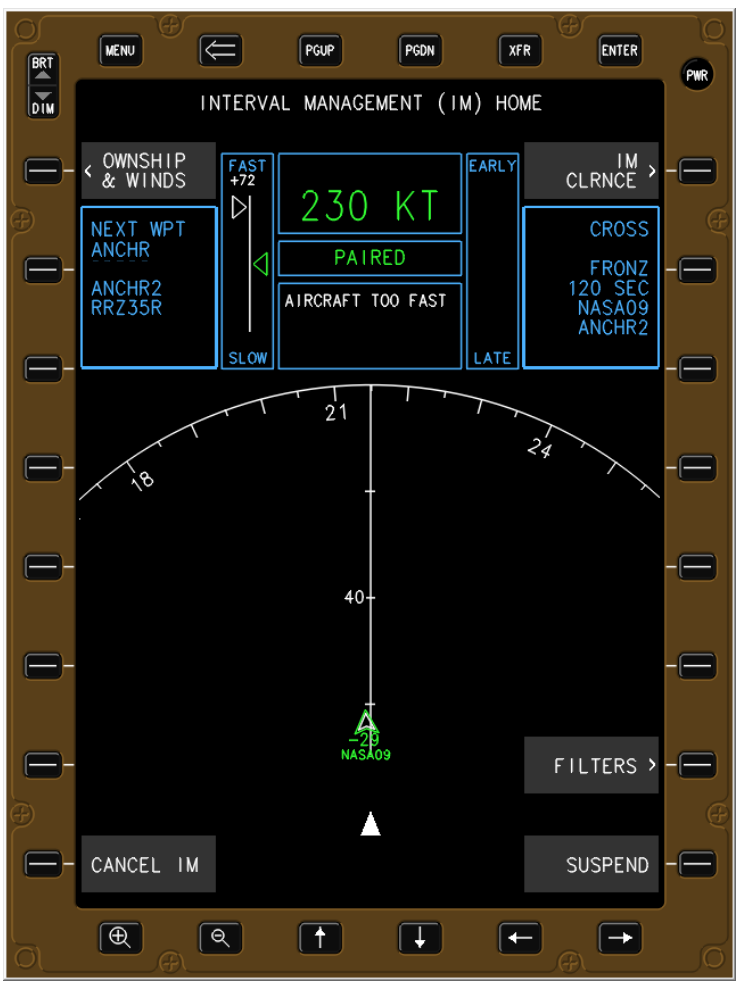

Figure 3. IM electronic flight bag display the use of IM in the midterm airspace environment. Since controller-pilot data link communications are not expected to be available in the midterm national airspace system, IM clearances are provided using voice communications and the intended trajectories of the IM and Traffic aircraft are assumed to be published Standard Terminal Arrival Routes (STARs). Additionally, the IM aircraft are assumed to have limited connectivity with the aircraft's flight management system, requiring the pilots to enter Ownship route information, wind information, and IM clearance information into an electronic flight bag (figure 3).

In preparation for the ATD-1 flight demonstration, several simulations were conducted to examine the integration of IM with TMA-TM and CMS. NASA's IM prototype has been continually refined based off of data gathered from these simulations. The refinements made to NASA's ASTAR spacing algorithm are of particular interest. Initial ATD-1 integrated simulations found that an earlier version of the ASTAR spacing algorithm, ASTAR11, did not perform well when used with TMA-TM and CMS. Since ASTAR uses the published STARs to estimate the Traffic aircraft's intended trajectory, the speeds expected by ASTAR and TMA-TM do not match when aircraft are delayed to resolve schedule conflicts. The ASTAR11 algorithm used a proportional speed control law that was not designed to compensate for large speed differences between the Traffic aircraft's actual speed and the published speeds that were used by ASTAR11 to predict the Traffic aircraft's ETA. As a result, when the Traffic aircraft was absorbing delay, the ASTAR11 algorithm provided commanded speeds that caused the spacing error to diverge to a steady state error value, causing undesirable closure rates between the IM and Traffic aircraft.

In 2013, NASA's ASTAR algorithm was updated to mitigate the previously described problems and improve compatibility with TMA-TM and CMS; the updated version of ASTAR was called ASTAR12. The primary modification was a ground speed term that was added to the ASTAR algorithm to compensate for 
variations between the Traffic aircraft's actual speeds and published speeds. The addition of the ground speed term prevents steady-state spacing errors from occurring when the Traffic aircraft is not flying its expected speed, reducing undesirable closure rates between the IM and Traffic aircraft. Both human-in-theloop simulations and fast-time simulations that investigated the performance of the ASTAR12 algorithm and its acceptability to pilots and controllers indicated that the ground speed term that was added to ASTAR12 improved compatibility with TMA-TM and CMS; however, there were cases where the ground speed term contributed to undesirable speed reversals. ${ }^{14,22,23}$

The ASTAR12 algorithm was updated to support the Capture, Cross, and Maintain operations that were investigated in this simulation; the updated version of ASTAR is called ASTAR13. The primary modification was a new state-based CTD speed control law that was added to support the Capture and Maintain operations, and the "maintain" phase of the Cross operation; that is, the phase that occurs after the IM aircraft crosses the achieve-by point.

\section{Experiment Design}

\section{A. Scenario Design}

This simulation modeled high density arrivals into Denver International Airport (KDEN). In order to calculate trajectories for the IM and Traffic aircraft, IM requires a continuous route from the en-route airspace to the planned termination point, which is typically the final approach fix in ATD-1 operations. KDEN was specifically chosen because all of the published STARs connect either to a Required Navigation Procedure (RNP) or Instrument Landing System (ILS) approach. Unlike current day operations at KDEN, simultaneous ILS and RNP approach operations were conducted to the same runway during this experiment. Aircraft on the downwind arrivals always flew the RNP procedure and aircraft on the straight-in approach always flew the ILS procedure.

The traffic scenarios simulated either north-flow or south-flow arrivals (figures 4 and 5), and either the east or west side of the airport was simulated for each of those airport configurations. Since only one side of the airport was simulated within a particular scenario, all of the aircraft in the simulated airspace flew arrivals to a single runway; either runway $35 \mathrm{~L}$ or $35 \mathrm{R}$ for the north flow scenarios and either runway $16 \mathrm{~L}$ or $17 \mathrm{R}$ for the south flow scenarios. ${ }^{\mathrm{a}}$

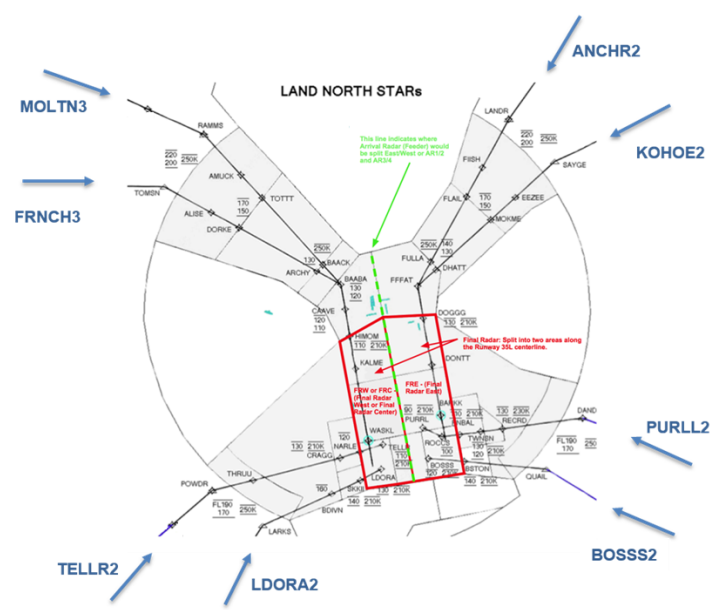

Figure 4. North-flow arrival procedures into Denver

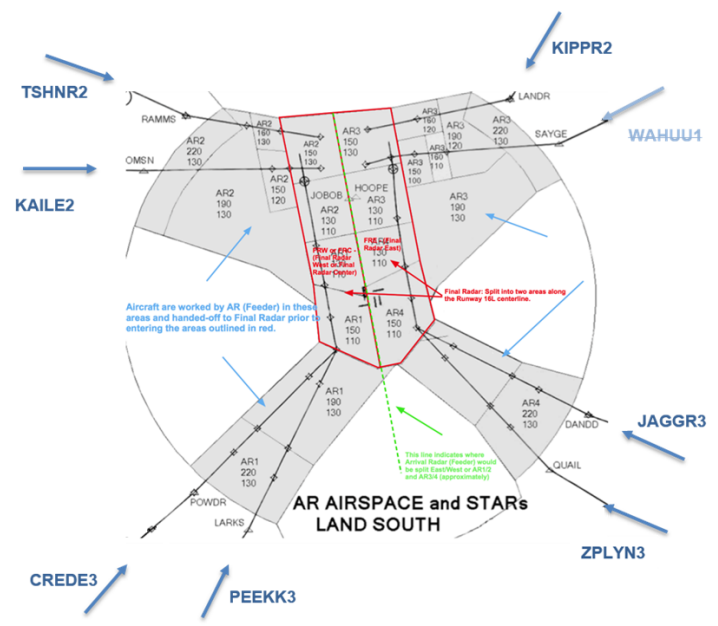

Figure 5. South-flow arrival procedures into Denver

Each scenario included six IM equipped aircraft flown by subject pilots and approximately 35 additional aircraft that were controlled by air traffic controllers using TMA-TM and CMS. All six IM equipped aircraft were initialized at a point prior to their top-of-descent and flew an arrival to the runway. During the applicable scenarios, IM clearances were provided to IM equipped aircraft in the Center airspace. The pilots were then expected to enter the clearance into on-board avionics and follow the IM commanded speeds to either achieve

a There were additional overflight aircraft and aircraft on the other side of the airfield that were simulated to provide a more realistic depiction of a high density environment on the air traffic controller scopes and on the pilots' navigation displays. These aircraft were not controlled by air traffic controllers and were not included in the data that were analyzed. 
or maintain a designated spacing goal. The air traffic controllers were responsible for controlling all aircraft that were not conducting IM operations and for maintaining safe separation of all aircraft.

A single truth wind and forecast wind were used throughout this simulation. ${ }^{\mathrm{b}}$ Denver airspace wind data over a one year period was analyzed to find a wind field that had similar characteristics to winds typically observed at Denver and that accommodated aircraft landing either to the north or the south. The truth and forecast wind fields that were selected had the following characteristics: the winds west of Denver were very strong, from the west, and varied little by altitude; the winds east of Denver were strong, from the west, and varied significantly by altitude; and the surface wind at KDEN was a light cross wind from the west. The difference between truth wind and forecast wind was small at FL350 and at 10,000 feet, and moderate at 5,000 feet.

\section{B. Independent Variables}

The independent variable in this experiment was the type of operation conducted, with values of Baseline, Capture, Cross, Maintain, and Mixed (table 1). A baseline condition with TMA-TM and CMS operations, but no IM operations, was included to allow for the comparison of system performance with and without IM operations. The Capture, Cross, and Maintain scenarios provided the ability to evaluate each IM clearance individually. In the Mixed scenarios, controllers had the flexibility to issue any of the three IM clearance types. The analysis within this paper does not include Mixed scenarios; however, those results can be found in a paper that summarizes the experiment results. ${ }^{26}$

Table 1. Experiment Matrix

\begin{tabular}{|c|c|c|c|c|}
\hline Baseline & Capture & Cross & Maintain & Mixed \\
Replicate 1 & Replicate 1 & Replicate 1 & Replicate 1 & Replicate 1 \\
Replicate 2 & Replicate 2 & Replicate 2 & Replicate 2 & Replicate 2 \\
\hline
\end{tabular}

Two replicates of each operation type were conducted - one with the Captain as the pilot flying and one with the First Officer as the pilot flying. Therefore, each flight crew flew a total of ten scenarios, and a within-subject design was utilized. The run order for the Baseline, Capture, Cross, and Maintain scenarios was partially counterbalanced using a Latin square design. ${ }^{27}$ These eight scenarios were followed by the two Mixed scenarios.

\section{Participants}

There were two groups of twelve pilots and four air traffic controllers that participated in this simulation; a total of 24 subject pilots and eight subject air traffic controllers. All of the pilots were either active line pilots or recently retired pilots with glass cockpit experience. Two of the air traffic controllers staffed the Center sectors and the remaining two air traffic controllers staffed the Feeder and Final sectors. All of the subject air traffic controllers were recently retired, and were required to have experience in their respective positions.

\section{Pilot and Controller Procedures}

In addition to their normal tasks, Center controllers were asked to achieve a meter fix delivery accuracy of 30 seconds or better. The Center controllers used delay countdown timers to determine the amount of delay that each aircraft had to absorb prior to the meter fix, and issued speed commands, altitude step-down instructions, or vectors to absorb the required amount of delay. The controllers were trained to wait until the delay to the meter fix was less than 60 seconds before issuing an IM clearance to ensure that the delay could be absorbed using speed control and to decrease the likelihood of a large delay difference between the IM and Traffic aircraft. Since the goal of the Maintain clearance was to maintain the current spacing interval between the IM and Traffic aircraft, the Center controllers were expected to wait until the aircraft had the desired spacing interval before issuing the Maintain clearance. After an aircraft began an IM operation,

\footnotetext{
${ }^{\mathrm{b}}$ The truth wind was from $10 / 21 / 2011$ at $18 \mathrm{Z}$ and the forecast wind was from $10 / 21 / 2011$ at $13 \mathrm{Z}$.
} 
the controllers were expected to monitor IM operations and intervene if there was an impending separation violation.

In addition to their normal tasks, the Terminal controllers were asked to use the CMS decision support tools to achieve the schedule calculated by TMA-TM. The Terminal controllers used the speed advisories and the slot markers (figure 2)to determine speeds required to achieve the STAs. The Terminal controllers were also expected to monitor IM operations and intervene if there was an impending separation violation. When Maintain operations were conducted, controllers were trained to terminate the IM clearance if the spacing interval between the IM and Traffic aircraft was no longer adequate, since the spacing goal did not necessarily reflect the schedule computed by TMA-TM.

In addition to their normal tasks, pilots were responsible for conducting IM operations. Before receiving an IM clearance, the pilots entered their route information and descent forecast winds into the IM avionics. After receiving an IM clearance, the pilots entered the clearance information into the electronic flight bag and activated the IM avionics. Once the IM speed was calculated, it was displayed to the pilots for them to evaluate if it was operationally acceptable or not. If it was, the pilots would press the "execute" button on their electronic flight bag to begin the IM operation. After the IM operation began, the pilots were responsible for monitoring for changes to the IM commanded speed and inputting them into the aircraft's mode control panel speed window. The pilots were able to contact air traffic control and cancel the IM clearance at any time if the IM commanded speeds were not acceptable. The ability to begin a Cross operation was inhibited until both the IM and Traffic aircraft were past the first speed constrained waypoint, since it was assumed that the IM aircraft did not have access to the Traffic aircraft's cruise information (an assumption that is consistent with the expected capability of the IM avionics during a future flight demonstration), and heuristics to estimate the cruise information were not developed for this simulation. Due to the location of the first speed constraint in the KDEN arrival procedures, the IM aircraft in the Cross scenario typically began their IM operations shortly after entering the Terminal airspace. The Capture and Maintain operations initiated in the Center airspace since the algorithm did not require the aircraft to have crossed a speed constrained waypoint.

\section{E. Facilities}

This simulation was conducted in both the Air Traffic Operations Laboratory and in the Flight Simulation Facility at the NASA Langley Research Center. For each group of pilots, four out of the six flight crews flew dual crew desktop simulators that emulated a large transport aircraft (figure 6). Each simulator contained a high fidelity six degree-of-freedom dynamics model and aircraft displays shown on three 27 -inch touchscreen monitors. Pilots interacted with the desktop simulators through either a mouse or touchscreen interface. Each desktop simulator was equipped with two emulated electronic flight bags running NASA's IM prototype software.

The remaining two flight crews flew high fidelity flight deck cabs located in the Flight Simulation Facility: the Development Test Simulator (DTS) and the Integration Flight Deck (IFD). Both of these simulators are high fidelity cabs that contain hardware from large transport aircraft and a full out the window view. Additionally, both of the cabs were equipped with two electronic flight bags that ran NASA's IM prototype software. The IFD, the highest fidelity aircraft simulator used, contains actual aircraft hardware and was flown on a motion base during this experiment (figure 7).

The Multi Aircraft Control System software was used to simulate air traffic controller stations and confederate pilot stations. The air traffic controller stations included one auxiliary station that was used to feed aircraft into the simulated sectors, two Center stations, a Feeder station, a Final station, and a Tower station (figure 8). The two Center stations, the Feeder station, and the Final station were staffed by subject air traffic controllers, and the other two stations were staffed by confederate air traffic controllers. Additionally, confederate pilot stations were used to both operate and provide voice communications for aircraft that were not flown by subject pilots.

\section{F. Spacing Algorithm Description}

The latest version of NASA's ASTAR spacing algorithm, ASTAR13, includes new functionality to support the Capture, Cross, and Maintain operations. ${ }^{24}$ The primary modification is the addition of a new statebased CTD speed control law that is used for the Capture and Maintain operations, and the "maintain" 


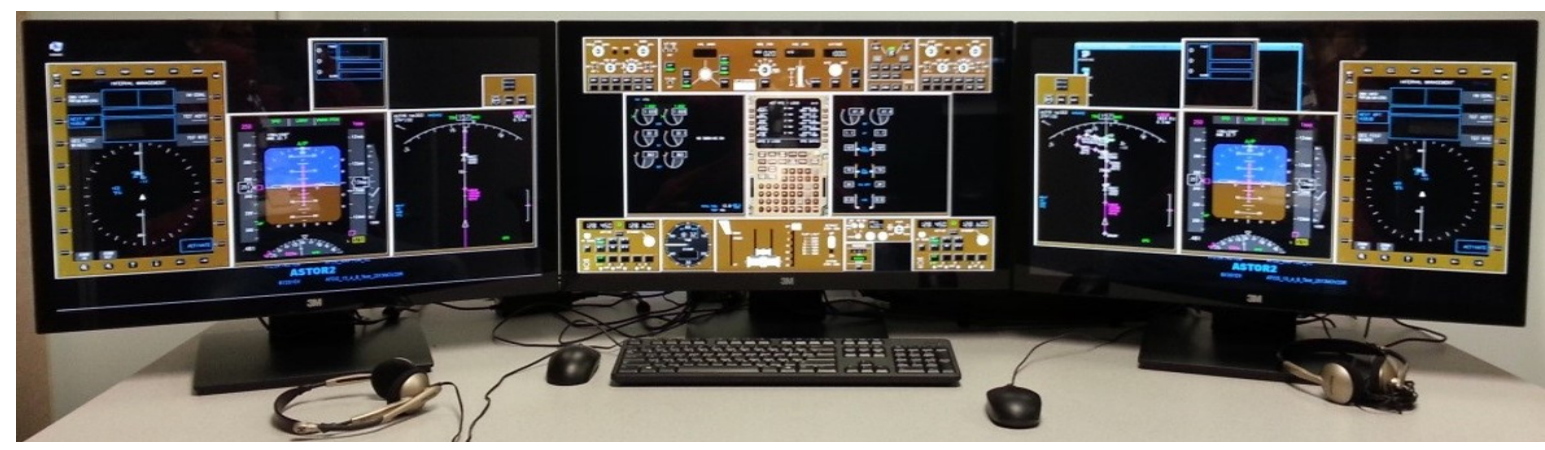

Figure 6. Dual crew desktop simulator

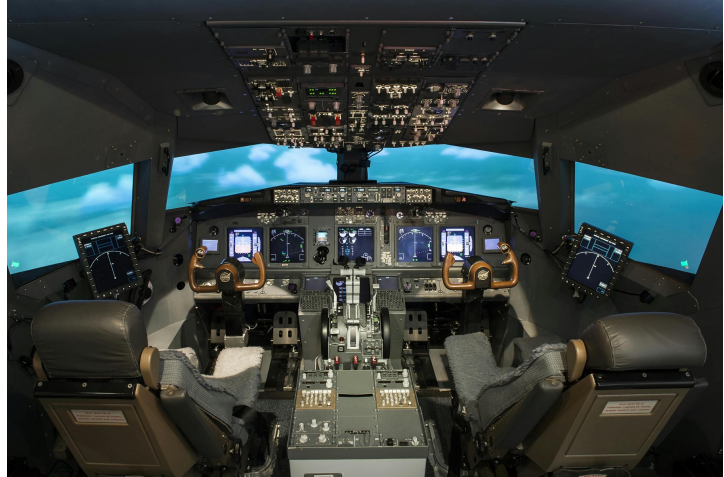

Figure 7. Integration Flight Deck (IFD)

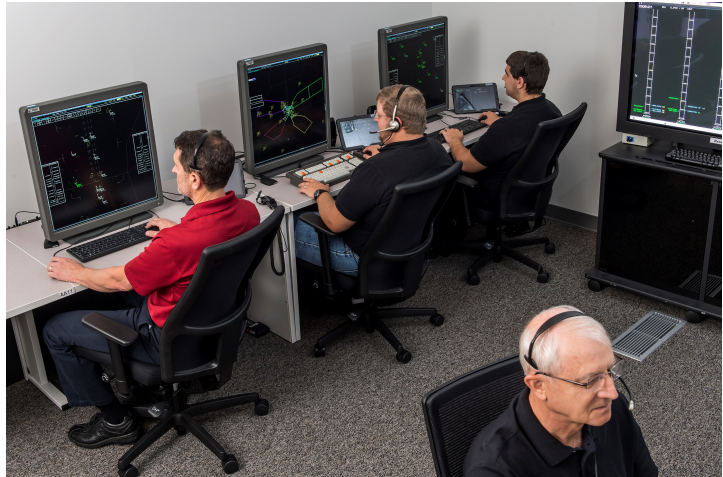

Figure 8. Air traffic controller stations

phase of the Cross operation. The trajectory-based speed control law used in the previous version of ASTAR is retained and is used for the "achieve" phase of the Cross operation.

\section{Trajectory-Based Speed Control Law}

The trajectory-based speed control law in ASTAR13 is designed to support IM operations both when the IM and Traffic aircraft are in-trail and when they are on merging routes. The spacing error is calculated using the time-to-go of the IM and Traffic aircraft along their predicted 4D-trajectories. For time-based operations (distance-based operations were not conducted in this simulation), the spacing error is defined as the difference between the IM aircraft's time-to-go $\left(T T G_{I M}\right)$ to the achieve-by point and the Traffic aircraft's time-to-go to the achieve-by point $\left(T T G_{T G T}\right)$ minus the spacing goal assigned by air traffic control $(\Delta)$.

$$
e(t)=T T G_{I M}(t)-T T G_{T G T}(t)-\Delta
$$

The amount of speed control required is computed using a proportional speed control law with a ground speed term added to compensate for differences between the Traffic aircraft's predicted ground speed and actual ground speed. The speed control is added to the IM aircraft's nominal speed to generate the IM commanded speed $\left(v_{c m d}(t)\right)$.

$$
v_{c m d}(t)=v_{n o m_{I M}}(t)+k_{p} e(t)+k_{G S}\left(v_{\operatorname{der}_{T G T}}(t)-v_{n o m_{T G T}}(t)\right)
$$

Here, $v_{n o m_{I M}}(t)$ is the nominal $4 \mathrm{D}$-trajectory airspeed of the IM aircraft; $k_{p}$ is the proportional gain, $e(t)$ is the spacing error; $k_{G S}$ is the gain for the ground speed term; $v_{d e r_{T G T}}(t)$ is the airspeed derived from the Traffic aircraft's ground speed, wind forecast, and altitude; and $v_{n o m_{T G T}}(t)$ is the nominal $4 \mathrm{D}$-trajectory airspeed of the Traffic aircraft.

The ATD-1 concept of operations assumes a retrofit implementation of IM that is not connected with the aircraft's flight management system, requiring the flight crew to monitor for IM speed changes and manually enter them into the aircraft's mode control panel speed window to close the control loop. To reduce the number of speed changes that the flight crew is required to respond to, speed commands are discretized into either five or ten knot increments before being displayed to the flight crew. 
Gain scheduling is implemented to ensure that the appropriate amount of speed control is used throughout the arrival. The proportional gain ranges from a value of 0.375 when the IM aircraft is far from the achieveby point to 1.5 when the IM aircraft is within 5 nautical miles (nmi) of the achieve-by point. The ground speed gain is set to one until the IM aircraft is $40 \mathrm{nmi}$ from the achieve-by point. Between $40 \mathrm{nmi}$ and 20 nmi from the achieve-by point, the ground speed gain is linearly decreased to zero, and remains at zero until the achieve-by point.

Additionally, the ground speed gain is set to zero whenever the Traffic aircraft's ground speed is faster than expected to reduce the number of instances where the trajectory-based speed control law commands a speed increase during an arrival. Additional filtering is applied to the Traffic aircraft's ground speed differential to prevent undesirable speed changes from occurring.

To prevent unacceptable IM commanded speeds, the commanded speed is limited to be within $15 \%$ of the nominal profile speed. The IM commanded speeds are also limited to conform with any airspace speed restrictions.

\section{CTD Speed Control Law}

The state-based CTD speed control law was added to ASTAR to support the Capture and Maintain operations, and the "maintain" phase of the Cross operation. Unlike the trajectory-based speed control law, the CTD speed control law can only be used when the IM and Traffic aircraft are on the same route.

For time-based operations, the measured spacing interval $(M S I(t))$ is calculated by determining the difference between the IM and Traffic aircrafts' actual times of arrival at a particular point along their common path. The spacing error at any given point is simply the difference between the measured spacing interval and the assigned spacing goal $(\Delta)$.

$$
e(t)=M S I(t)-\Delta
$$

The amount of speed control required is computed using a proportional speed control law and the Traffic aircraft's estimated time-history airspeed. The Traffic aircraft's time-history airspeed is estimated using the IM aircraft's sensed winds along with the ground speed and altitude of the Traffic aircraft when it was at the IM aircraft's current along path position. The speed control is added to the Traffic aircraft's derived time-history airspeed to generate the IM commanded speed.

$$
v_{c m d}(t)=v_{d e r_{T G T}}(t-M S I(t))+k_{p} e(t)
$$

Here, $v_{\operatorname{der}_{T G T}}(t-M S I(t))$ is the Traffic aircraft's estimated time-history airspeed, $k_{p}$ is the proportional gain, and $e(t)$ is the spacing error. Similarly to the trajectory-based speed control law, the pilots are required to manually enter the commanded speeds into their aircraft's mode control panel to close the control loop; therefore, the speed commands are discretized into either five or ten knot increments. The commanded speed is also limited to be within $15 \%$ of the nominal profile speed and limited to conform to any airspace speed restrictions.

Gain scheduling is implemented to ensure that the appropriate amount of speed control is used throughout the arrival. The gains used in the CTD speed control law range from 0.5 to 1.5, and depend on the IM aircraft's along-path distance to the planned termination point and the magnitude of the spacing error.

There were some cases where the gains were not high enough to meet the capture rate specified in the IM standards; therefore, an override function was implemented. Whenever the speed control, $k_{p} e(t)$, is less than $5 \%$ of the IM aircraft's nominal airspeed and the spacing error is greater than 20 seconds, the magnitude of the speed control is increased so that it is equal to $5 \%$ of the IM aircraft's nominal airspeed.

Additional heuristics are used to minimize the number of speed commands provided to the flight crew. One of these heuristics is a function that uses the Traffic aircraft's time-history information to estimate the speed that the Traffic aircraft had at the end of a long deceleration, resulting in fewer speed commands when the Traffic aircraft has a large speed change.

\section{G. Training and Data Collection Methodology}

All controllers and pilots participated in one week of training, followed by one week of data collection approximately one month later. Pilots completed a computer-based training program prior to arriving at NASA Langley, whereas the controllers did not receive any prior training or information. The week of 
training included classroom presentations, part-task simulations, and fully integrated simulation. During the week of data collection, pilots and controllers received an additional day of refresher training that was followed by three days of data collection.

The data that were collected included both qualitative and quantitative information. Qualitative data were collected from both pilots and controllers through post-scenario questionnaires, post-experiment questionnaires, and feedback obtained during post-experiment group debriefing sessions. The quantitative data that were collected included aircraft state data, IM algorithm performance data, data from the TMA-TM and CMS ground systems, and pilot and controller performance data.

\section{Results}

The results that are presented in this paper are focused on the integration of IM with TMA-TM and CMS. Since the goal of TMA-TM and CMS is to help controllers achieve precise schedule conformance and the goal of IM is to help pilots achieve or maintain a precise spacing interval, metrics for both schedule conformance and spacing interval conformance are discussed.

\section{A. Schedule Conformance at the Final Approach Fix}

The schedule conformance at the final approach fix is the difference in time between an aircraft's STA at the final approach fix and its actual time of arrival. Throughout this simulation, controllers used TMA-TM and the CMS decision support tools to help aircraft that were not conducting IM operations achieve their scheduled times of arrival, whereas aircraft conducting IM operations used IM avionics to achieve or maintain a precise spacing interval. Since the IM aircraft were controlled to a spacing interval instead of the schedule, it was expected that the IM aircraft and non-IM aircraft would have similar schedule deviations.

The schedule conformance at the final approach fix for both IM and non-IM aircraft are shown in figure 9 and table 2. The "IM" category includes all aircraft that were conducting IM operations when they were at the final approach fix and the "non-IM" category contains all aircraft that were not conducting IM operations, including aircraft with IM operations that were canceled earlier in the arrival.

The results indicate that the mean schedule conformance of both IM and non-IM aircraft in the Baseline, Capture, Cross, and Maintain scenarios were similar; all arriving slightly later than their STAs. Furthermore, the standard deviation of the schedule conformance was similar for both IM and non-IM aircraft in the Capture and Cross scenarios. The aircraft in the Baseline scenario had a larger standard deviation than the aircraft in the Capture and Cross Scenarios. The primary reason for this difference was a small number of outliers in the Baseline scenario. For the Maintain operation, the standard deviation of the schedule conformance at the final approach fix was larger for IM equipped aircraft than for non-IM aircraft because the spacing goal calculated by the IM avionics often did not match the TMA-TM schedule.

Previous research that examined the behavior of strings of IM aircraft has shown that the standard deviation of the schedule conformance associated with the last aircraft in a string increases as a function of string length. ${ }^{23,28}$ This simulation included strings of up to four IM aircraft. The schedule conformance was plotted as a function of aircraft sequence for each scenario to determine if it degraded as a function of string

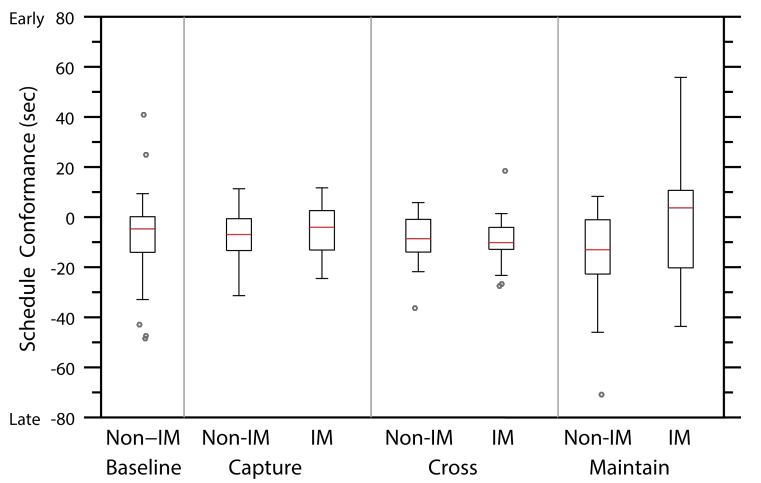

Table 2. Schedule conformance at the final approach fix

\begin{tabular}{ll|ccc}
\hline Scenario & Operation & Mean (sec) & SD (sec) & N \\
\hline Baseline & Non-IM & -7.9 & 17.3 & 33 \\
Capture & Non-IM & -7.7 & 10.4 & 23 \\
& IM & -4.7 & 10.0 & 20 \\
Cross & Non-IM & -8.9 & 10.1 & 20 \\
& IM & -8.9 & 9.7 & 24 \\
Maintain & Non-IM & -14.2 & 17.2 & 29 \\
& IM & 0.4 & 29.4 & 12 \\
\hline
\end{tabular}

Figure 9. Schedule conformance at the final approach fix 
position (figure 14 in the Appendix). Within figure 14, a string of IM aircraft is a consecutive sequence of filled in blue squares. A visual inspection of the data suggests that changes to the schedule conformance as a function of string position were relatively small for the Capture and Cross operations. There were large schedule deviations observed during the Maintain scenario; however, they were primarily caused by a mismatch between the spacing goal and the TMA-TM schedule.

\section{B. Inter-arrival Spacing Error at the Final Approach Fix}

The primary goal of IM is to increase the spacing precision at a flow constricted point, such as the final approach fix. In order for IM operations to provide increased throughput, IM operations must provide greater spacing precision than TMA-TM and CMS. The expected spacing precision for TMA-TM and CMS (i.e., Terminal Sequencing and Spacing) is a standard deviation of 12 seconds, whereas spacing errors less than 10 seconds $95 \%$ of the time are desired for IM operations, ${ }^{29}$ which corresponds to a standard deviation of approximately five seconds if the data are normally distributed.

The inter-arrival spacing error at the final approach fix is a measure of how well the spacing interval between an aircraft and the preceding aircraft matched the difference between the aircrafts' STAs. The inter-arrival schedule error is calculated using the following equation:

$$
\text { Inter-arrival Spacing Error }=\left(A T A_{i}-A T A_{i-1}\right)-\left(S T A_{i}-S T A_{i-1}\right)
$$

Here, $A T A_{i}$ is the actual time of arrival of the aircraft of interest, $A T A_{i-1}$ is the actual time of arrival of the preceding aircraft that arrived at the final approach fix, $S T A_{i}$ is the scheduled time of arrival of the aircraft of interest, and $S T A_{i-1}$ is the scheduled time of arrival or the preceding aircraft. For all of the IM operations except Maintain, the difference between the scheduled times of arrival, $\left(S T A_{i}-S T A_{i-1}\right)$, was equal to the spacing goal provided to the IM aircraft. Similarly to the schedule deviation metric, all of the aircraft in the "IM" category were conducting IM operations at the final approach fix.

The results in figure 10 and table 3 indicate that the IM aircraft in the Capture scenario had a standard deviation that was 5.2 seconds less than the non-IM aircraft in the Capture scenario and 13.1 seconds less than the aircraft in the Baseline scenario. The IM aircraft in the Cross scenario had a standard deviation that was 8.2 seconds less than the non-IM aircraft in the Cross scenario and 13.0 seconds less than the aircraft in the Baseline scenario. The improvement in the spacing precision of IM aircraft in the Capture and Cross scenarios are similar to the desired amount, indicating that they provided the expected benefit.

Within this simulation, the spacing precision of the non-IM aircraft in the Capture and Cross scenarios was less than the spacing precision of the aircraft in the Baseline scenario. The results in figure 15, which shows the inter-arrival spacing error for each scenario, indicate that there was one particular Baseline run where the inter-arrival spacing error had more variability than the other Baseline runs. Figure 14 shows that the same Baseline run also had high schedule conformance variability.

The results from the Maintain scenario indicate that spacing precision of the IM aircraft was better than the non-IM aircraft in the Maintain scenario, but worse than the IM aircraft in the Capture and Cross scenarios, primarily because the spacing goal used by aircraft conducting Maintain operations often did not match the TMA-TM schedule. Even though the IM aircraft in the Maintain scenario were controlled to a

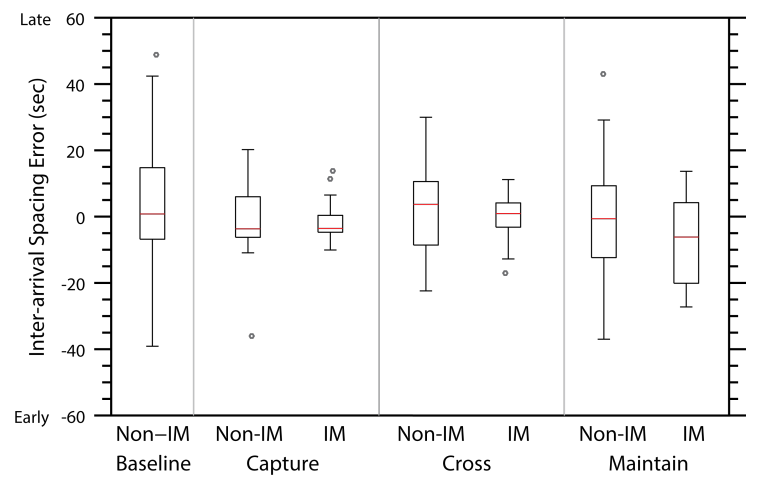

Table 3. Spacing error at the final approach fix

\begin{tabular}{llccc}
\hline Scenario & Operation & Mean (sec) & SD (sec) & N \\
\hline Baseline & Non-IM & 4.1 & 19.2 & 33 \\
Capture & Non-IM & -1.2 & 11.3 & 23 \\
& IM & -1.5 & 6.1 & 20 \\
Cross & Non-IM & 2.4 & 14.4 & 20 \\
& IM & -0.1 & 6.2 & 24 \\
Maintain & Non-IM & -1.2 & 17.5 & 29 \\
& IM & -7.3 & 13.8 & 12 \\
\hline
\end{tabular}

Figure 10. Spacing error at the final approach fix 
spacing interval that did not match the schedule, they were typically able to precisely maintain that spacing interval throughout the arrival.

Previous research has investigated the string stability of various IM speed control laws. A speed control law is considered to be string stable if perturbations to the spacing error are reduced as a function of string position. The results of these studies indicate that the trajectory-based speed control law used in ASTAR13 is string stable, ${ }^{23}$ whereas time-history speed control laws, such as the CTD speed control law used in ASTAR13, are not string stable. ${ }^{30}$ The inter-arrival spacing error at the final approach fix was plotted as a function of aircraft sequence for each scenario to determine if the spacing error increased as a function of string position (figure 15 in the Appendix). A visual inspection of figure 15 did not reveal any large increases in the inter-arrival spacing error as a function of string position, suggesting that the inter-arrival spacing error exhibited acceptable string behavior during this simulation.

\section{Schedule Conformance at the Meter Fix}

The schedule conformance at the meter fix was analyzed to determine if IM operations had an adverse effect on the meter fix delivery accuracy. Since the goal of an IM operation is to either achieve or maintain a single spacing goal, the IM aircraft were not controlled to meet the scheduled interval at the meter fix. The goal of this analysis was to determine if the schedule conformance of the IM aircraft were sufficiently close to the schedule conformance of the non-IM aircraft.

Similarly to the schedule conformance at the final approach fix, the schedule conformance at the meter fix was measured as the difference in time between an aircraft's scheduled time of arrival and its

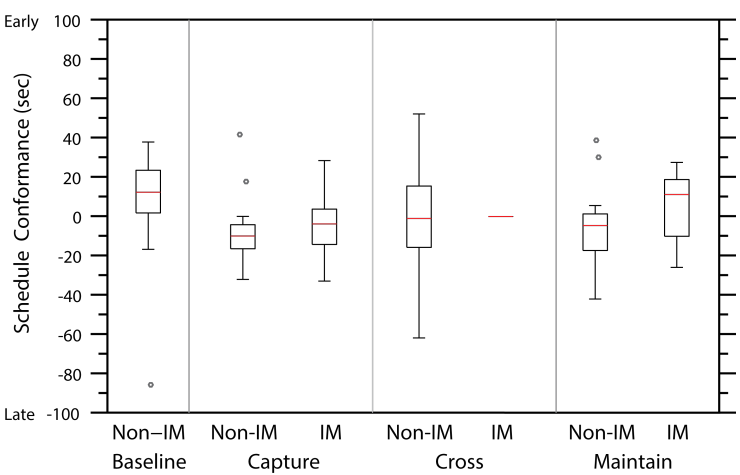

Figure 11. Schedule conformance at the meter fix actual time of arrival. Within this simulation, the Center controllers were asked to achieve a schedule conformance of 30 seconds or better at the meter fix.

The results indicate that there were differences between the schedule conformance of IM aircraft and the schedule conformance of non-IM aircraft at the meter fix; however, the differences observed in the Baseline, Capture, and Maintain scenarios are relatively small and were not rated as problematic by controllers. (figure 11). Additionally, the distance between consecutive aircraft at the meter fix was always greater than 6.5 nmi, indicating that there were no separation violations at the meter fix.

The meter fix schedule conformance of the non-IM aircraft in the Cross scenario had greater variability than the other conditions. When Cross operations were conducted, all but one of the IM aircraft initialized IM operations shortly after entering the Terminal airspace, because they were required to cross a speed constrained waypoint before they were allowed to initiate IM operations. Further examination of the data indicated that the large variability was caused by aircraft that initiated IM operations inside the Terminal airspace. While it is difficult to confirm, it is possible that Center controllers were more apprehensive about providing aircraft speed commands between the time when the IM clearance was provided and when the IM operation was initiated. Designing heuristics to estimate cruise information for the Traffic aircraft would have alleviated the need to begin IM operations after the first speed constrained waypoint and allowed the IM aircraft to begin spacing earlier in the arrival, potentially resulting in improved meter fix schedule conformance.

\section{Slot Marker Deviation}

Slot markers are a component of the CMS decision support tools that provide Terminal controllers with a graphical depiction of an aircraft's scheduled location (figure 2). Within this simulation, Terminal controllers used slot markers and speed advisories to determine speeds that they could provide to aircraft that were not conducing IM operation to help them achieve the TMA-TM schedule. Slot markers were also shown for aircraft that were conducting IM operations to provide Terminal controllers with a reference position that they could use to judge whether an IM operation was progressing as expected. For example, if the Traffic 
aircraft was a certain distance away from its slot marker, air traffic controllers would expect that the IM aircraft would either be the same distance from its slot marker or closing on that position.

The slot marker deviation was analyzed to determine if there were any differences between IM and non-IM aircraft. Since the goal of IM is to achieve or maintain a specific spacing interval behind another aircraft, the expectation was that the slot marker deviation of IM and non-IM aircraft would be similar. The along-path slot marker deviation was calculated and plotted as a function the normalized distance-to-go between the meter fix and the final approach fix (figure 12). For each distance-to-go value, aircraft that were conducing IM operations were included in the IM aircraft dataset and aircraft that were not conducing IM operations were included in the non-IM aircraft dataset. The blue line in figure 12 shows the mean along-path slot marker deviation of the non-IM aircraft and the blue shaded region shows one standard deviation. Similarly, the red line shows the mean slot marker deviation of the IM aircraft and the red shaded region shows one standard deviation.

The data in figure 12 indicates that the IM and non-IM aircraft in the Capture scenario had similar mean slot marker deviations and similar standard deviations, suggesting that Capture operations generally conformed well with the CMS decision support tools.

In the Cross scenario, both the IM and non-IM aircraft started with a substantial amount of slot marker deviation, which converged toward zero as the aircraft approached the final approach fix. On average, the IM aircraft were approximately one nautical mile ahead of the slot marker until they were close to the final approach fix. There are three primary reasons for this behavior. First, the goal of the Cross operation is to achieve the spacing goal at the achieve-by point, which was the final approach fix within this simulation; therefore, the spacing error may not converge to zero until the aircraft is close to the achieve-by point. Secondly, the distance at which the ground speed term in the trajectory-based speed control law was phased out caused the spacing error to be biased early in a number of cases. Section G contains a detailed description of this behavior. A third contributing factor was instances where the IM commanded speed was limited to $15 \%$ of the published speeds and could not slow down enough to reduce the spacing error. The large changes in the mean slot marker deviation of the IM aircraft close to the meter fix were caused by several aircraft that initiated IM operations shortly after they crossed the meter fix.

In the Maintain scenario, the standard deviation of the slot marker deviation of the IM aircraft did not decrease as the aircraft approached the final approach fix. This is due to the fact that the spacing goal of the Maintain operation did not reflect the TMA-TM schedule.

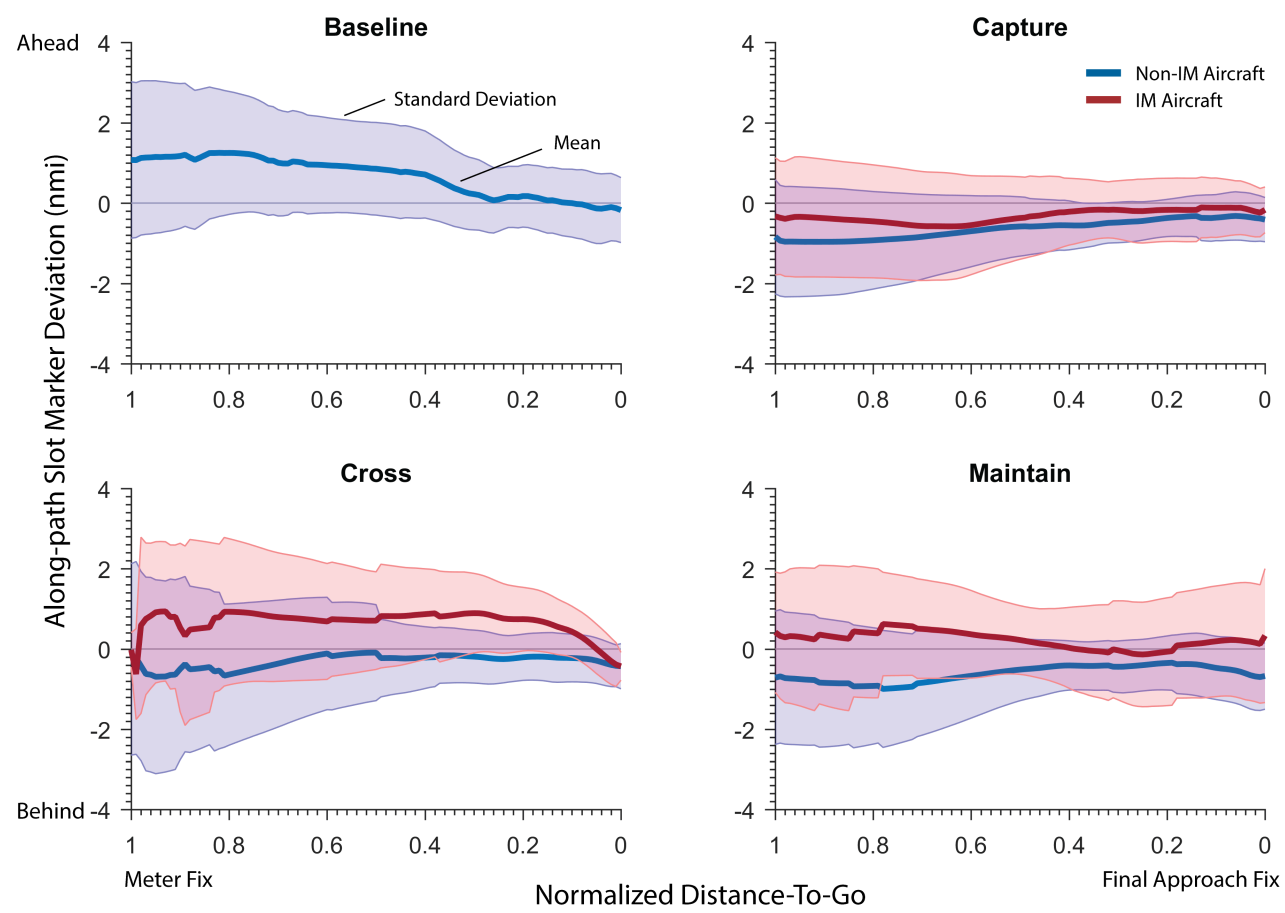

Figure 12. Along-path slot marker deviation 


\section{E. Relative Slot Marker Deviation}

Terminal controllers used the relative positions of the IM and Traffic aircraft to their respective slot markers as an indication of whether an IM operation was progressing as expected. In order to calculate the relative slot marker deviation, the runway arrival sequence was determined. The relative slot marker deviation is the difference between the slot marker deviation of the aircraft of interest and the slot marker deviation of the preceding aircraft in the runway arrival sequence. Similarly to the inter-arrival spacing error, negative values indicate that the aircraft's along-path positions were too close to each other and positive values indicated that the aircrafts' along-path positions were not close enough (i.e., too far).

The results in figure 13 indicate that the relative slot marker deviation of the IM aircraft in the Capture scenario had a less variability than the non-IM aircraft, suggesting that the traffic flow was better organized when Capture operations were used.

Since a majority of the IM aircraft conducting Cross operations were not able to initiate that operation until entering the Terminal airspace, they started with a similar amount of relative slot marker deviation as the non-IM aircraft. Throughout the arrival, the relative slot marker deviation of the non-IM aircraft tended to be too far from each other, whereas the IM aircraft were too close. The IM aircraft tended to be too close to the preceding aircraft due to a combination of several factors that include the impact of the phasing out the ground speed term in the trajectory-based speed control law (see section G for details), and the fact that the goal of the Cross operation is to achieve the spacing goal at the achieve-by point. Similarly to the slot marker deviation metric, the large changes in the mean relative slot marker deviation of the IM aircraft at the meter fix were caused by IM aircraft initializing IM operations just as the aircraft entered Terminal airspace, resulting in those aircraft being switched from the non-IM category to the IM category.

The relative slot maker deviation of the IM aircraft in the Maintain scenario had less variability than the non-IM aircraft when they entered the Terminal airspace; however, both the mean and standard deviation of the relative slot marker deviation did not converge to zero as the IM aircraft approached the final approach fix. As previously discussed, this was a result of the spacing goal not reflecting the TMA-TM schedule.

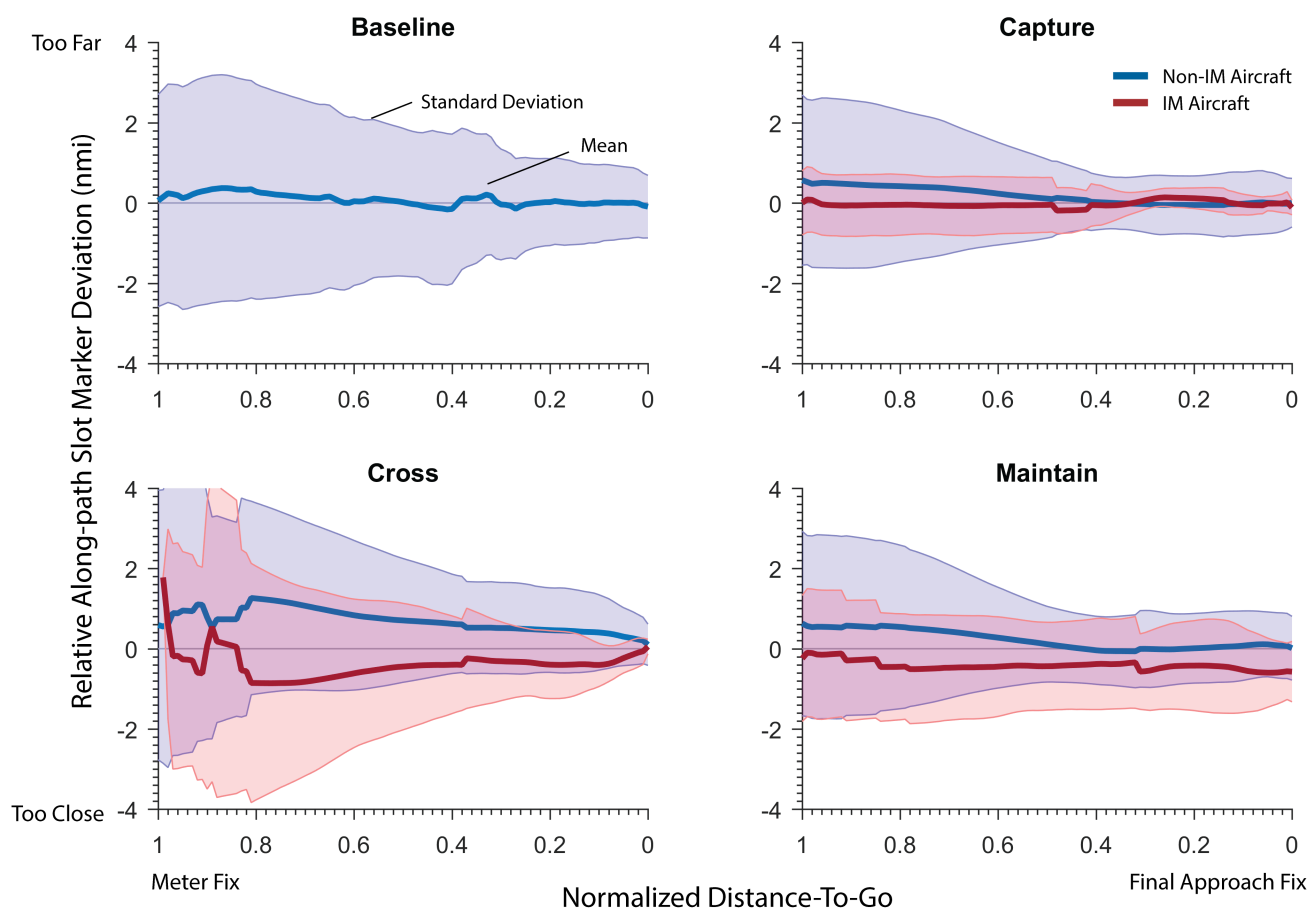

Figure 13. Relative along-path slot marker deviation

\section{F. IM Interruptions}

An interruption was counted each time an IM aircraft was canceled or suspended and never resumed. There were no cases of IM operations being interrupted by flight crew, and a total of 14 IM operations 
interrupted by air traffic controllers. By IM operation, three out of 23 (13\%) interruptions occurred during Capture operations, one out of the 24 (4\%) occurred during Cross operations, and ten out of the 20 $(50 \%)$ occurred during Maintain operations. The primary reasons for the interruptions in the Capture and Cross scenarios were instances where the air traffic controllers forgot that an aircraft was conducting an IM operation and issued the aircraft a speed command, and one case during a Capture operation where an air traffic controller canceled the IM operation to avoid slowing the aircraft behind the IM aircraft. The IM interruptions during the Maintain scenario were expected, since controllers were trained to cancel the Maintain operation if the spacing interval between the IM and Traffic aircraft was no longer desirable.

\section{G. Trajectory-based Speed Control Law Ground Speed Term}

The analysis of the slot maker deviation and relative slot marker deviation showed that the IM aircraft in the Cross scenario were typically ahead of their slot markers and had a relative slot marker deviation that indicated that the IM and Traffic aircraft were too close. One contributing factor to this behavior was the decision to inhibit the ground speed term in the trajectory-based speed control law when the IM aircraft is close to the achieve-by point. The rationale for this design decision was the expectation that the Traffic aircraft would finish absorbing delay prior to the achieve-by point, and fly speeds that were close to their published speeds. However, the route designs and adaptation used in this simulation allowed the Traffic aircraft to absorb delay much closer to the achieve-by point than originally anticipated.

When the Traffic aircraft is absorbing delay close to the achieve-by point (i.e., after the ground speed term is phased out), the trajectory-based speed control law will provide commanded speeds that cause the spacing error to diverge from zero to a steady state error value. This problem occurs because the trajectorybased speed control law only uses proportional control when the ground speed term is turned off. Therefore, there must be a certain amount of spacing error present for the IM aircraft to match the Traffic aircraft's speed deviation.

In order to help characterize this behavior, an analytic analysis of the steady state error was conducted for the case where the ground speed term in ASTAR13 is inactive (i.e., $k_{G S}=0$ ), and the case where the ground speed term is active (i.e., $k_{G S}=1$ ). As is often the case with analytical analyses, several simplifying assumptions are made:

- the conversion from airspeed to groundspeed is not modeled;

- various filters and heuristics used by ASTAR are not modeled;

- the IM aircraft's nominal speed is assumed to be constant;

- the Traffic aircraft's speed and nominal speed are assumed to be constant;

- the IM aircraft's speed $\left(v_{I M}\right)$ is equal to the IM commanded speed $\left(v_{c m d}\right)$; and

- the nominal speed of the Traffic aircraft is equal to the nominal speed of the IM aircraft.

In order to calculate the steady state error, a differential equation for the spacing error is determined, a Laplace transformation is used to convert the spacing error to the frequency domain, and the final value theorem is used to determine the steady state error that will occur as time approaches infinity.

The spacing error is defined as the difference between the time-to-go of the IM and Traffic aircraft minus the spacing goal (equation 1). The estimated time-to-go of the IM aircraft and the Traffic aircraft are simply their respective distance-to-go divided by their nominal speed. Using this relationship, the spacing error and time derivative of the spacing error can be calculated (equations 6 and 7 , respectively).

$$
\begin{gathered}
e(t)=\frac{D T G_{I M}(t)-D T G_{T G T}(t)}{v_{\text {nom }}}-\Delta \\
\dot{e}(t)=\frac{v_{c m d}(t)-v_{T G T}}{v_{\text {nom }}}-\Delta
\end{gathered}
$$


The following derivation examines the steady state-error for the case where the ground speed term is equal to zero (i.e, $k_{G S}=0$ ), causing ASTAR13 to revert to proportional control. The differential equation for the spacing error is calculated by combining equations 2 and 7 and setting $k_{G S}$ to zero.

$$
\begin{gathered}
\dot{e}(t)=\frac{\left(v_{\text {nom }}+k_{p} e(t)\right)-v_{T G T}}{v_{\text {nom }}}-\Delta \\
\dot{e}(t)-\frac{k_{p}}{v_{\text {nom }}} e(t)=1-\frac{v_{T G T}}{v_{\text {nom }}}
\end{gathered}
$$

Next, equation 9 is converted to the frequency domain using a Laplace transformation, and the resulting expression is simplified.

$$
\begin{gathered}
s E(s)-\frac{k_{p}}{v_{\text {nom }}} E(s)=\left(1-\frac{v_{T G T}}{v_{\text {nom }}}\right) \frac{1}{s} \\
E(s)=\frac{v_{\text {nom }}-v_{T G T}}{v_{\text {nom }} s^{2}-k_{p} s}
\end{gathered}
$$

The steady state error is calculated using the Final Value Theorem, which states that the steady stateerror is the $\lim _{s \rightarrow 0} s E(s)$.

$$
e_{s s}=\frac{v_{T G T}-v_{\text {nom }}}{k_{p}}
$$

Equation 12 shows that the steady state error of the trajectory-based speed control law is the difference between the Traffic aircraft's nominal ground speed and actual ground speed divided by the proportional gain. Therefore, when the Traffic aircraft's ground speed is lower than expected, such as when the Traffic aircraft is absorbing delay, the trajectory-based speed control law will command speeds that control the IM aircraft to an early (negative) steady-state error value.

The same process can be used to show that steady-state error of the trajectory-based speed control law is zero when the ground speed term is fully active (i.e., $k_{G S}=1$ ). Therefore, phasing out the ground speed term will be problematic if the Traffic aircraft is still absorbing delay and if the proportional gain is not large enough.

One method of solving this problem is to extend the ground speed term to the achieve-by point; however, fast-time simulations have shown that this can result in IM commanded speed increases close to the achieve-by point that pilots would likely find unacceptable. Further investigation is needed to understand the trade-off between the improved spacing error response and increase in speed changes associated with extending the ground speed term, and to determine if there are alternative methods of solving this problem.

\section{H. Additional IM and Ground System Integration Considerations}

This section describes additional considerations that should be made when evaluating the integration of IM operations with TMA-TM and CMS. These considerations include the impact of altitude decreases in the Center airspace, the impact of unknown delay during trajectory-based IM operations, and the impact of wind conditions that cause the required spacing interval at the meter fix to be more constraining than the spacing interval at the final approach fix.

Center controllers typically provide aircraft with vectors, speed commands, or altitude reductions to absorb delay. Within this simulation, there was a case during a Capture operation where an altitude reduction provided to the Traffic aircraft caused undesirable IM speed commands. The controllers provided the Traffic aircraft with an altitude decrease and did not provide a similar altitude decrease to the IM aircraft, causing a large ground speed difference between the IM and Traffic aircraft. The CTD speed control law commanded a slow airspeed to compensate for the ground speed difference. Later in the arrival, the Traffic aircraft rejoined its original altitude profile. The airspeed commanded by the CTD algorithm increased since there was no longer an altitude difference between the IM and Traffic aircraft. Since the state-based CTD speed control law uses the Traffic aircraft's time-history ground speed (equation 4), the speed reversal propagated through a string of three IM aircraft. Even though the example described above is a Capture operation, similar behavior could occur any time that the CTD speed control law is used (i.e., during both Capture and Maintain operations and during the "maintain" phase of the Cross operation). The 
trajectory-based speed control law is less susceptible to mismatches between the IM and Traffic aircrafts' altitudes because their trajectories are recomputed whenever their altitudes deviate significantly from their trajectories. Further procedure or algorithm development is needed to prevent similar cases from occurring during future IM operations. One potential solution is for the controllers to reduce the altitude of the IM aircraft whenever they reduce the altitude of the Traffic aircraft.

Another potential integration challenge is caused by unknown delay during Cross operations. Within the ATD-1 concept of operations, the IM avionics use the speed and altitude constrains on the published STARs to estimate the time-to-go of the IM and Traffic aircraft. As a result, the delay computed by TMA-TM is not able to be input into the IM avionics. This may cause IM to command speeds that do not correspond with the speeds needed to achieve schedule conformance, potentially causing integration issues with surrounding non-IM aircraft. This problem was not observed in this simulation; however, all but one of the aircraft conducting Cross operations initialized IM shortly after entering the Terminal airspace. Therefore, the amount of delay is less than it would have been if IM had been initialized earlier in the Center airspace. Future work is needed to determine the conditions, if any, where unknown delay causes integration problems between IM aircraft conducting Cross operations and non-IM aircraft.

Previous research demonstrated that there were a small percentage of wind conditions where the spacing interval required at the meter fix is smaller than the spacing interval required at the final approach fix. ${ }^{31}$ These conditions occur when there is a small headwind at the achieve-by point and a large headwind at the meter fix. While this problem was not observed within this simulation, it should be considered when determining requirements for the integration of IM operations with TMA-TM and CMS.

\section{Conclusion}

A human-in-the-loop simulation was conducted to investigate the integration of the Capture, Cross, and Maintain IM operations with TMA-TM and CMS (also known as Terminal Sequencing and Spacing). During the simulation, air traffic controllers used TMA-TM and the CMS decision support tools to achieve precise schedule conformance, and pilots used IM avionics on-board their aircraft to achieve or maintain a precise spacing interval behind the preceding aircraft.

The Capture and Cross operations generally integrated well with TMA-TM and CMS and provided the desired improvement in spacing precision at the final approach fix. The standard deviation of the inter-arrival spacing error of aircraft conducting Capture operations was 5.2 seconds less than the non-IM aircraft in the Capture scenario and 13.1 seconds less than the Baseline scenario. Similarly, the standard deviation of aircraft conducting Cross operations was 8.2 seconds less than the non-IM aircraft in the Capture scenario and 13.0 seconds less than the aircraft Baseline scenario. The slot marker deviations of aircraft conducting Capture operations and non-IM aircraft were similar, suggesting acceptable conformance with the CMS decision support tools. The mean slot marker deviation of aircraft conducting Cross operations was approximately one nautical mile ahead of their slot markers until they were close to the final approach fix. One reason for this behavior was a ground speed term in the trajectory-based speed control law that was phased out when the aircraft were between 20 and 40 nautical miles from the achieve-by point. Both the Capture and Cross operations had a low number of controller interventions, suggesting that controllers generally found them acceptable.

Maintain operations resulted in less precise schedule conformance and larger slot marker deviations close to the final approach fix than non-IM aircraft. The primary reason for this was that the spacing goal calculated by the IM avionics when the Maintain operation was initialized often did not match the TMA-TM schedule.

Even though a majority of the IM operations in this simulation were successful, a single wind field and a limited number of air traffic scenarios were investigated. Further work is needed to determine whether these results can be extrapolated to a larger range of wind conditions and traffic scenarios.

\section{Appendix}

Figure 14 shows the schedule deviation at the final approach fix as a function of aircraft sequence for each run and figure 15 shows the inter-arrival spacing error as a function of aircraft sequence for each run. The non-filled blue circles indicate aircraft that were flown by confederate pilots, the non-filled blue squares indicate aircraft that were flown by subject pilots and not conducting IM operations at the final approach fix, 
and the filled blue squares indicate aircraft that were flown by subject pilots and conducting IM operations at the final approach fix. Within this simulation, the first two aircraft in each arrival were removed since they were not representative of high density operations, and the aircraft that were later in the arrival sequence than the last subject pilot flown aircraft were removed since they did not land before the end of the scenario. Additional gaps in the data are due to aircraft that were removed because of simulation anomalies. Figures 14 and figure 15 indicate that the schedule deviation and inter-arrival spacing error did not grow as a function of aircraft sequence. 


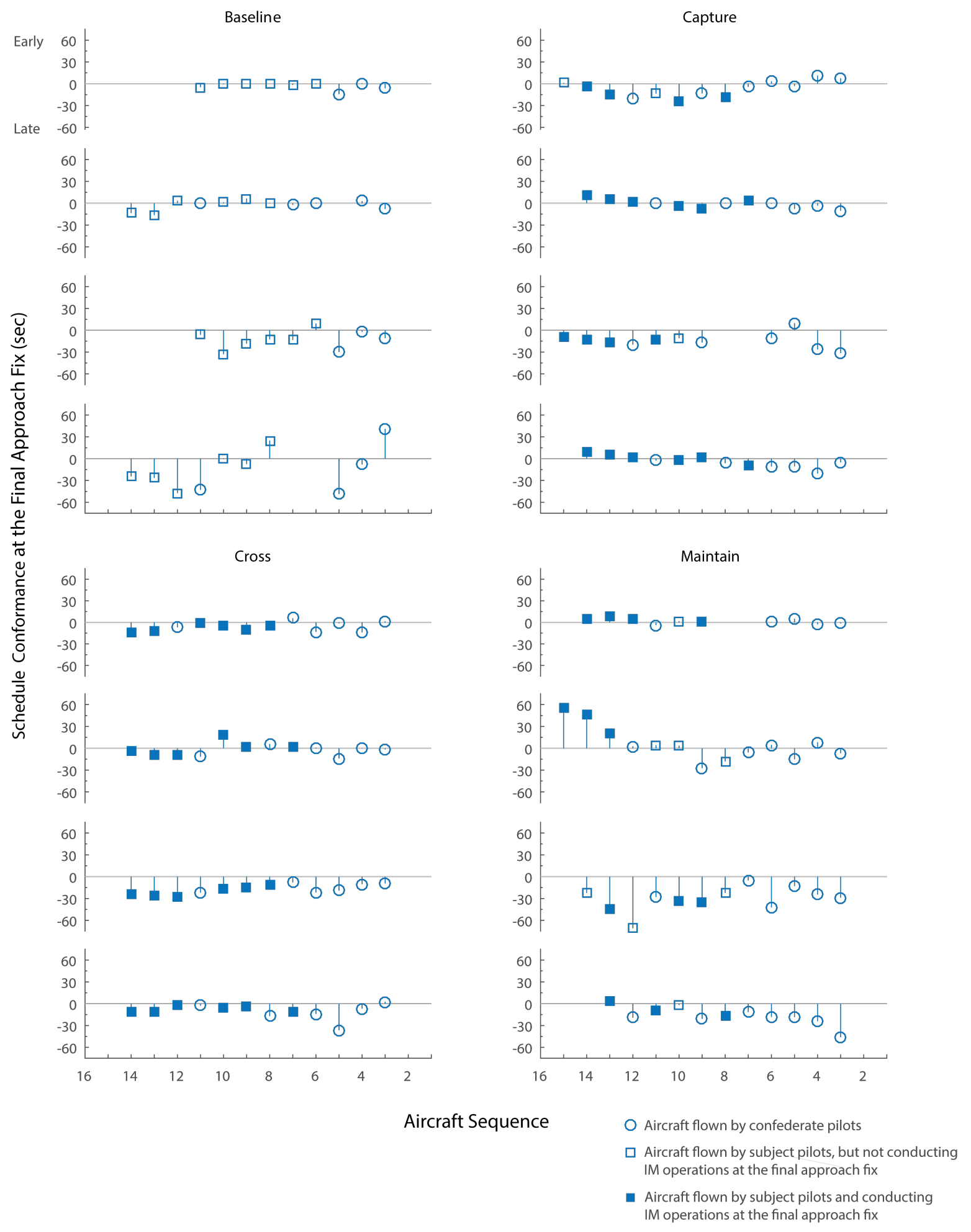

Figure 14. Schedule conformance at the final approach fix as a function of aircraft sequence 

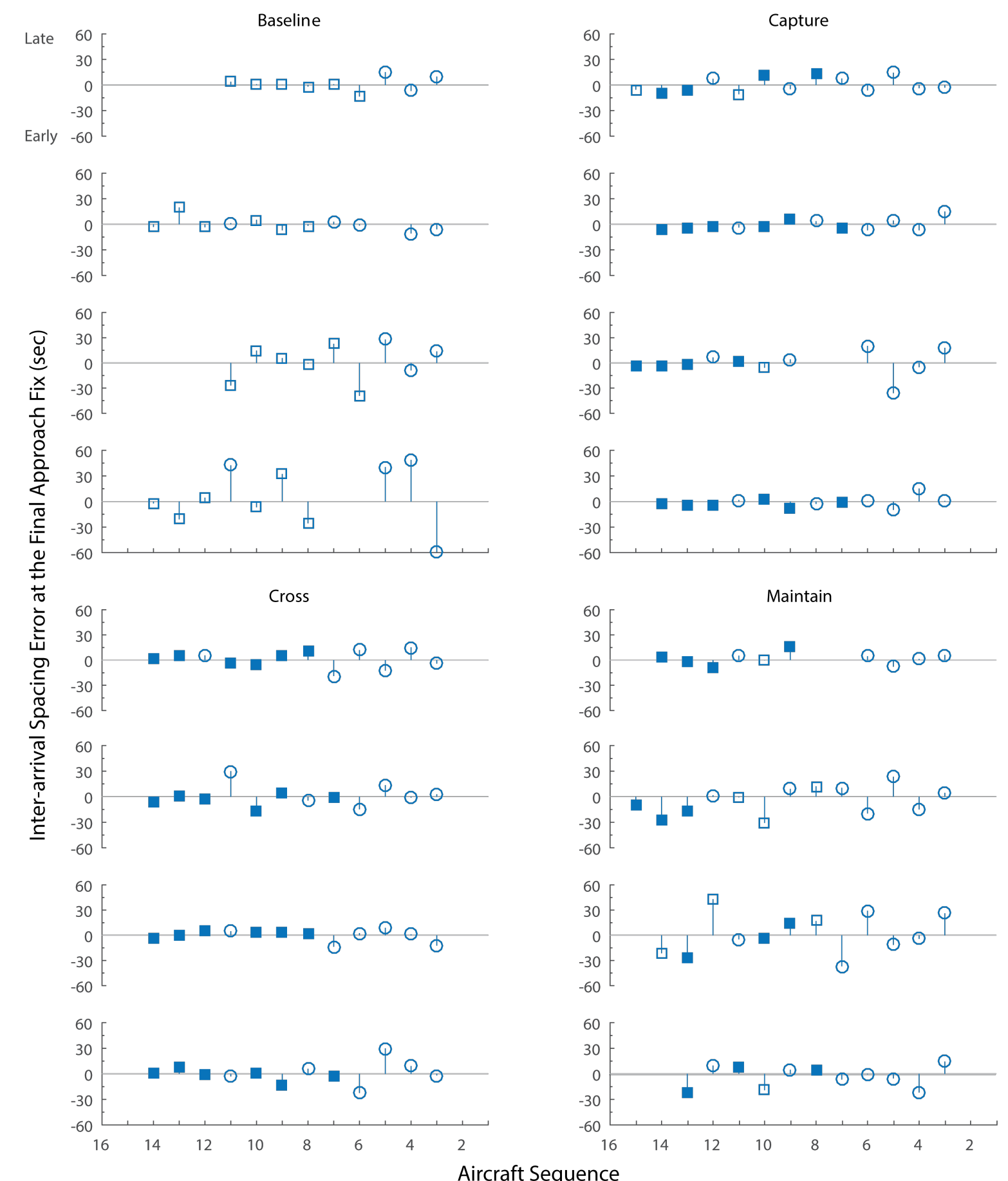

Aircraft Sequence

Aircraft flown by confederate pilots

$\square$ Aircraft flown by subject pilots, but not conducting IM operations at the final approach fix

- Aircraft flown by subject pilots and conducting IM operations at the final approach fix

Figure 15. Inter-arrival spacing error at the final approach fix as a function of aircraft sequence 


\section{Acknowledgments}

The authors gratefully acknowledge the hard work invested by the software development teams at NASA Langley Research Center and the important contributions of the software development team at NASA Ames, without either of which this experiment would not have occurred.

\section{References}

1"FAA Aerospace Forecast: Fiscal Years 2015-2035," US Department of Transportation Federal Aviation Administration Aviation Policy and Plans, 2015.

${ }^{2}$ Robinson, J. and Kamgarpour, M., "Benefits of Continuous Descent Operations in High-density Terminal Airspace Under Scheduling Constraints," 10th AIAA Aviation Technology, Integration, and Operations (ATIO) Conference, Fort Worth, TX, 2010, pp. 13-15.

${ }^{3}$ Baxley, B., Swenson, H., Prevot, T., and Callantine, T., "NASA's ATM technology demonstration-1: Integrated Concept of Arrival Operations," Digital Avionics Systems Conference (DASC), 2012 IEEE/AIAA 31st, IEEE, 2012, pp. 3B1-1.

${ }^{4}$ Baxley, B., Johnson, W., Swenson, H., Robinson, J., Prevot, T., Callantine, T., Scardina, J., and Greene, M., "Air Traffic Management Technology Demonstration-1 Concept of Operations (ATD-1 ConOps)," NASA/TM-2013-218040, Aug 2012.

${ }^{5}$ Isaacson, D. R., Robinson III, J. E., Swenson, H., and Denery, D., "A Concept for Robust, High Density Terminal Air Traffic Operations," 10th AIAA Aviation Technology, Integration, and Operations (ATIO) Conference, Fort Worth, TX, 2010.

${ }^{6}$ Swenson, H. N., Thipphavong, J., Sadovsky, A., Chen, L., Sullivan, C., and Martin, L., "Design and Evaluation of the Terminal Area Precision Scheduling and Spacing System," Ninth USA/Europe Air Traffic Management Research and Development Seminar (ATM) Berlin, Germany, 2011.

${ }^{7}$ Callantine, T., Palmer, E., and Michael, K., "Human-in-the-loop Simulation of Trajectory-based Terminal-area Operations," 27th International Congress of the Aeronautical Sciences (ICAS), Nice, France, 2010.

${ }^{8}$ Kupfer, M., Callantine, T., Martin, L., Mercer, J., and Palmer, E., "Controller Support Tools for Schedule-based Terminalarea Operations," Proceedings of the Ninth USA/Europe Air Traffic Management Research and Development Seminar, 2011.

${ }^{9}$ Robinson III, J. E., Thipphavong, J., and Johnson, W. C., "Enabling Performance-Based Navigation Arrivals," Eleventh USA/Europe Air Traffic Management Research and Development Seminar (ATM2015), Lisbon, Portugal, 2015.

${ }^{10}$ Barmore, B. E., Abbott, T. S., Capron, W. R., and Baxley, B. T., "Simulation Results for Airborne Precision Spacing Along Continuous Descent Arrivals," perspective, Vol. 22, 2008, pp. 27.

${ }^{11}$ Murdoch, J. L., Barmore, B. E., Baxley, B. T., Capron, W. R., and Abbott, T. S., "Evaluation of an Airborne Spacing Concept to Support Continuous Descent Arrival Operations," Eighth USA/Europe Air Traffic Management Research and Development Seminar (ATM2009), Napa, CA, 2009.

${ }^{12}$ Thipphavong, J., Jung, J., Swenson, H. N., Witzberger, K. E., Lin, M. I., Nguyen, J., Martin, L., Downs, M. B., and Smith, T. A., "Evaluation of the Controller-Managed Spacing Tools, Flight-deck Interval Management and Terminal Area Metering Capabilities for the ATM Technology Demonstration \#1," USA/Europe ATM REDD Seminar (ATM2013), Chicago, Illinois, 10-13 June 2013.

${ }^{13}$ Callantine, T. J., Kupfer, M., Martin, L., Mercer, J., and Prevot, T., "System-Level Performance Evaluation of ATD-1 Ground-Based Technologies," 14th Aviation Technology, Operations, and Integration Conference, Atlanta, 2014, pp. 16-20.

${ }^{14}$ Wilson, S. R., Kibler, J. L., Hubbs, C. E., and Smail, J. W., "Air Traffic Management Technology Demostration-1 Research and Procedural Testing of Routes," , May 2015.

${ }^{15}$ RTCA, "Minimum Operational Performance Standards (MOPS) for Flight-deck Interval Management (FIM)," DO-361, 2015.

${ }^{16}$ Murdoch, J., Wilson, S., Hubbs, C., and Smail, J., "Acceptability of Flight deck-based Interval Management Crew Procedures," AIAA Modeling and Simulation Technologies Conference and Exhibit, AIAA Paper 2013-5155, Boston, MA, Boston, MA, August 19-22 2013.

${ }^{17}$ Wilson, S., Murdoch, J., Hubbs, C., and Swieringa, K., "Evaluation of Flight Deck-Based Interval Management Crew Procedure Feasibility," AIAA Modeling and Simulation Technologies Conference and Exhibit, AIAA Paper 2013-5155, Boston, MA, August 19-22 2013.

${ }^{18}$ Barmore, B. E., Abbott, T. S., and Capron, W. R., "Evaluation of Airborne Pprecision Spacing in a Human-in-the-loop Experiment," AIAA 5th Aviation Technology, Integration, and Operations (ATIO) Conference), 2005, pp. 26-28.

${ }^{19}$ Brian, B., Murdoch, J., Swieringa, K., Barmore, B., Capron, W., Hubbs, C., Shay, R., and Abbott, T., "Experiment Description and Results for Arrival Operations Using Interval Management with Spacing to Parallel Dependent Runways (IMSPiDR)," NASA/TP-2013-217998.

${ }^{20}$ Swieringa, K., Murdoch, J., Baxley, B., and Hubbs, C., "Evaluation of an Airborne Spacing Concept, On-board Spacing Tool, and Pilot Interface," 11th AIAA Aviation Technology, Integration, and Operations (ATIO) Conference, Virginia Beach, VA, September 20-22 2011.

${ }^{21}$ Swieringa, K. A., Wilson, S. R., and Shay, R., "An Evaluation of Retrofit Flight Deck Displays for Interval Management," 14th AIAA Aviation Technology, Integration, and Operations (ATIO) Conference, Atlanta, GA, June 16-20 2014.

${ }^{22}$ Swieringa, K. A., Underwood, M. C., Barmore, B., and Leonard, R. D., "An Evaluation of a Flight Deck Interval Management Algorithm including Delayed Target Trajectories," 14th AIAA Aviation Technology, Integration, and Operations Conference, Atlanta, GA, June 16-20 2014.

${ }^{23}$ Swieringa, K. A., "The String Stability of a Trajectory-Based Interval Management Algorithm in the Midterm Airspace," 15th AIAA Aviation Technology, Integration, and Operations Conference, 2015, p. 2278. 
${ }^{24}$ Abbott, T. S., "An Overview of a Trajectory-Based Solution for En Route and Terminal Area Self-Spacing: Seventh Revision," NASA/CR-2015-218794, 2015.

${ }^{25}$ Credeur, L., "Basic Analysis of Terminal Operation Benefits Resulting from Reduced Vortex Separation Minima," NASA/TM-78624, 1977.

${ }^{26}$ Baxley, B., Wilson, S., Swieringa, K., Johnson, W., Roper, R., Hubbs, C., Goess, P., and Shay, R., "Description and Results of the Interval Management Alternative Clearances (IMAC) Experiment," NASA/TP, 2016.

${ }^{27}$ Dean, A. and D., V., Design and Analysis of Experiments, 1999.

${ }^{28}$ Levitt, I. M., Weitz, L. A., Barmore, B. E., and Castle, M. W., "Modeling Delay and Delivery Accuracy for Mixed Absolute and Relative Spacing Operations," 14th AIAA Aviation Technology, Integration, and Operations Conference, Atlanta, GA, 16-20 June 2014.

${ }^{29}$ RTCA, "Safety, Performance and Interoperability Requirements Documents for Airborne Spacing-Flight Deck Interval Management (ASPA-FIM)," DO-328A, 2015.

${ }^{30}$ Weitz, L. and Hurtado, J., "String Stability Analysis of Selected Speed Control Laws for Interval Management," AIAA Guidance, Navigation, and Control Conference, 2012.

${ }^{31}$ Robinson, J. E., "Calculation of Flight Deck Interval Management Assigned Spacing Goals Subject to Multiple Scheduling Constraints," Digital Avionics Systems Conference (DASC), 2014 IEEE/AIAA 33rd, IEEE, 2014, pp. 1B4-1. 